\title{
Editorial
}

\section{Economies: An Open Access Journal for the Field of Development Macroeconomics}

\author{
Ralf Fendel \\ Editor-in-Chief of Economies, Chair of Monetary Economics, Economics Group, \\ WHU - Otto-Beisheim-School of Management, Burgplatz 2, D-56179 Vallendar, Germany; \\ E-Mail: Ralf.Fendel@whu.edu; Tel.: +49-261-6509-284; Fax: +49-261-6509-289.
}

Received: 4 January 2013 / Accepted: 10 January 2013 / Published: 17 January 2013

Economies (ISSN 2227-7099) is a new international, peer-reviewed open access journal for the academic fields of development economics and macroeconomics. While the latter seems to be clearly defined, development economics is not, because it is related to nearly all traditional economic sub-disciplines such as macroeconomics, international trade and finance, as well as microeconomics and public finance. Typically, academic field journals of development economics cover all those economic sub-disciplines. Economies instead focuses mainly on the macroeconomic perspective of economic development and it intends to publish academic research that is of strong macroeconomic policy relevance. In general, contributions in Economies should foster understanding of the macroeconomic process of economic development, with the process of development not exclusively being reserved to what we typically call developing countries. Also, the group of developed economies is still developing in the sense of improving their living standards further.

The title of this new journal intends to indicate its intention and scope. It is about the whole economy respectively the Economies that all together form the world economy and it is about how to increase the wealth of Economies. This guiding theme of the journal can be seen in the long tradition of the publication that forms the foundation of the discipline of economics: "An Inquiry into the Nature and Causes of the Wealth of Nations" by the Scottish political philosopher Adam Smith dating back to 9 March 1776. Today, almost 236 years later-despite all academic research-we still lack a complete understanding of the "nature and causes of wealth". However, today, we should rather think of interrelated "Economies" instead of individual "Nations", because we believe that-like international trade-economic development is not a "zero sum game". Successful economic development of one economy does not limit other economies' economic development; instead it potentially supports it. Furthermore, development is not limited to economic growth, so we should interpret Adam Smith's wealth of nations not to be limited to GDP levels. 


\section{Why This New Journal?}

There are already a number of high-quality field journals that cover economic development topics. However, as previously outlined, Economies will have a sharper focus on the macro-development aspect. Despite the difference in its focus, another reason for this new journal is the dissatisfaction among researchers with the currently observed publication processes. The usual complaints are the tremendous publication delays, the "market power" of the editors and the high prices for institutional subscriptions that publishers often require. Economists know that many of those shortcomings can be mitigated by increased competition and one important aspect of competition is the number of suppliers of outlets for research results. Economies is such a new and innovative outlet.

Economies will take a different route than established journals and draws on MDPI's experience: the journal will follow successful peer-reviewing practices from the natural sciences, which put a lot of the burden on the managing editors rather than the editorial board members to ensure a fast refereeing and publication process. Further - as for all other MDPI journals-Economies is strictly open access, meaning that no reader and no institution will ever be charged for access to research published in Economies. Costs of production are covered through modest article processing charges (APCs). This is quite similar to submission fees, but paid only if the article is accepted. MDPI will waive the APCs for the first two years. APCs are still uncommon in economics publishing, but they are widespread and well-established in the natural sciences. In sum, open access publishing is much less costly for researchers as they are typically both authors and readers of scientific journals.

\section{What and How Economies Will Publish}

Economies will publish original research articles, reviews, and short research notes. Emphasis is on applied empirical and analytical work. As already outlined, the contributions should be from development economics focusing on its macro-development dimension as well as from closely related fields. The latter include but are not limited to, sustainable growth, international income distribution, natural resources, productivity developments and macroeconomic policies. Submissions of historical and interdisciplinary studies that contribute to the understanding of development are also welcome. Contributions in Economies are not restricted to any special group of economies.

Economies will provide a much faster avenue for knowledge dissemination than the traditional, still paper-based journals, and one which is universally accessible. It aims at an open-minded, comprehensive coverage of research in development macro-economics. This includes research that might not follow the mainstream in economic thinking. After a rigorous peer review process within which editorial delays will be carefully avoided, accepted papers will be published online immediately, with issues closed on a quarterly basis. No restrictions are placed on the length of regular research articles. Instead, we encourage authors of original research articles to provide as much detail as needed to assure accessibility for readers. Authors of empirical articles are encouraged to share their data and codes, so that results are reproducible. Authors of analytical work are encouraged to provide the details of proof and methods applied.

Reviews on any aspects that fall into the scope of Economies are welcome; in particular those reviews which keep in mind that the potential audience includes practitioners of development policy. 
Short notes are focused contributions addressing a specific issue of interest and may also report negative results (e.g., empirical work which did not produce the "desired" effect).

Economies provides a unique opportunity to improve the research communication both within the community of academics in development economics as well as between academics and practitioners in development policies. On behalf of the Editorial Board of Economies, I kindly invite you to submit your work to Economies and share the results of your academic research with a broad interested audience.

(C) 2013 by the authors; licensee MDPI, Basel, Switzerland. This article is an open access article distributed under the terms and conditions of the Creative Commons Attribution license (http://creativecommons.org/licenses/by/3.0/). 